\title{
O LEGADO DA ESCOLA DO RECIFE PARA A FORMAÇÃO DOS CURSOS JURÍDICOS NO BRASIL E SUAS CRÍTICAS.
}

\author{
Alberto de Moraes Papaléo Paes ${ }^{1}$ \\ Frederico Antônio Lima de Oliveira ${ }^{2}$ \\ Jeferson Antônio Fernandes Bacelar ${ }^{3}$
}

Resumo:

O presente artigo parte da premissa de que a Escola do Recife desempenhou um papel significante na fundação da crítica jurídica e exerceu uma forte influência para juristas do país todo. Pretende-se, portanto, descrever sobre o que foi o movimento crítico do surto de novas ideias proposto pela Escola do Recife, ao passo que, fornecer um panorama geral da formação dos outros cursos jurídicos no Brasil que foram influenciados pelos professores de Recife, seja na continuidade das ideias jurídicas, seja pelo fato terem estudado durante o período de efervescência da produção crítica.

Palavras-chave: Escola do Recife, Ensino Jurídico, Continuidade, Originalidade, Crítica.

\section{THE LEGACY OF RECIFE'S SCHOOL ON THE FORMATION OF JURIDICAL TEACHING IN BRAZIL AND ITS CRITIQUES.}

Abstract:

This article is based on the premise that Escola do Recife played a significant role in the foundation of legal criticism and exerted a strong influence on jurists across the country. It is intended, therefore, to describe what was the critical movement of the surge of new ideas proposed by Escola do Recife, while providing an overview of the formation of other legal courses in Brazil that were influenced by teachers from Recife, either in the

\footnotetext{
${ }^{1}$ Doutor em Direitos Humanos pela Universidade Federal do Pará (UFPA); Mestre e Bacharel em Direito pela Universidade da Amazônia (UNAMA); Professor Universitário das Disciplinas de Filosofia Geral e Jurídica, Hermenêutica e Argumentação Jurídica e Direito Constitucional da Universidade da Amazônia (UNAMA) e Faculdade Maurício de Nassau (UNINASSAU) na Graduação e Pós-graduação lato sensu; Pesquisador vinculado ao Grupo de Estudos de Hermenêutica Constitucional (GEHC) e Efetividade dos Direitos Fundamentais (GEEDF) vinculados ao Programa de Pós-graduação em Direitos Fundamentais da Universidade da Amazônia (PPGDF-UNAMA); Avaliador de Periódicos Qualis-CAPES; Professor Colaborador do Instituto Teológico Quadrangular da Igreja do Evangelho Quadrangular (ITQ-IEQ Pedreira); Advogado em Belém-PA; e-mail: betomppaes@msn.com ID Orcid: https://orcid.org/00000003-0248-1226 Currículo Lattes: http://lattes.cnpq.br/3902863915145828

${ }^{2}$ Pós-doutor em Direito na Faculdade de Direito da Universidade de Lisboa (FDUL - Portugal); Doutor em Direito de Estado pela Pontifícia Universidade Católica de São Paulo (PUC-SP); Mestre em Direito Público pela Universidade Federal do Pará (UFPa). Professor da Universidade da Amazônia (UNAMA) na graduação e na Pós-Graduação Lato e Stricto Sensu.

${ }^{3}$ Doutor em Direitos Fundamentais e Novos Direitos na UNESA-RJ (2018). Mestre em Direito do Estado pela Universidade da Amazônia (2009 É Coordenador Geral dos Cursos de Direito do Grupo Ser Educacional. Professor Titular da Universidade da Amazônia -UNAMA, na graduação e na Pós-Graduação Lato e Stricto Sensu.
} 
continuity of legal ideas, or because they studied during the period of effervescence of critical production.

Keywords: Recife's School, Juridical Teaching, Continuity, Originality, Critique.

\section{Introdução}

Durante o início da década de 60, no século XIX, inicia no Brasil o movimento da Escola do Recife que empreende uma crítica contumaz ao espiritualismo, ao ecletismo e ao jusnaturalismo aderindo a argumentos considerados positivistas e darwinistas, somente depois da publicação do texto de Sylvio Romero "A morte da Metafísica”, que a Escola do Recife encontra seu grande apogeu. Marcada pela contribuição inicial de Tobias Barreto de Menezes e a introdução do germanismo no Brasil este movimento também pode ser caracterizado como a porta de entrada de diversas orientações importantes para a filosofia no Brasil e para o Direito. Torna-se, por oportuno, um período que fica marcado como conceitua Sônia Gomes (1986), pela postura crítica que as elites assumem na defesa da modernização e das estruturas sociais desenvolvendo um projeto mais coerente com a realidade nacional da época (p. 13). Ou seja, trata-se de um movimento que não é apenas epistêmico, ou, filosófico, mas também de renovação cultural.

A complexidade das teses e sua apresentação variada faz com que este cenário seja alvo de diversos encantos e, por ventura, eles podem guiar a uma, ou, outra precipitação. Neste sentido é importante salientar que a pesquisa não terá o propósito de descrever minuciosamente cada uma das ideias novas e críticas que foram feitas pelos autores deste período, mas, sim a de compreender o que significou a Escola do Recife enquanto um movimento político, cultural, ideológico, filosófico e jurídico que imprimiu uma marca indelével na tradição jurídica brasileira. Isto levará, naturalmente, a uma pesquisa historiográfica pautada na proposta de uma História das Ideias e do pensamento jurídico no Brasil. Acredita-se, por oportuno que existe (ainda) um relativo desinteresse em realizar pesquisas neste sentido, por isso há uma escassez bibliográfica e materiais interessados no tema. 
O Problema de Pesquisa pode ser sintetizado na forma da seguinte pergunta: Qual foi o legado deixado pela Escola do Recife na formação dos cursos jurídicos no Brasil? Como questões norteadoras elencamos: a) No que consistiu o movimento crítico denominado de Surto de Novas Ideias?; b) Como se deu a expansão desse surto na formação dos cursos jurídicos pelo Brasil? e; c) Quais foram as principais críticas opostas à Escola do Recife? Em conclusão pretende-se fornecer uma síntese das questões que foram abordadas ao longo do trabalho e, na medida do possível, tentar responder algumas das críticas que foram levantadas ao longo da pesquisa.

Utilizando-se o método da metáfora, a exemplaridade, a tarefa, neste momento, será tal qual a do investigador criminal que, dada a comunicação e o conhecimento da ocorrência de um crime, precisa descobrir quem é o criminoso. Bem, as perguntas que ele deve fazer são bastante claras, porém, o modo de constituir a narrativa do crime é, impressionantemente, difícil. O investigador começa do fim, da conclusão, alguém foi assassinado. E partir deste evento ele precisa buscar elementos para que a história seja contada de ponta-cabeça, ou, inversamente. $\mathrm{O}$ assassino pode ter entrado por essa porta, ou, escalado essa janela, pode ter vindo a pé, ou dirigindo, pode ser medir tanto, pesar tanto, ter vindo dali, ou, daqui; suas intenções são essa, ou aquela. Como foi dito: uma árdua tarefa de contar a história "do avesso".

Tal qual o investigador se está diante do fim da história. A Escola do Recife se opôs ao Jusnaturalismo e ao Ecletismo Espiritual, insurgiu-se através de uma adesão a uma metodologia de orientação positivista e partir daí desenvolveu o Culturalismo Jurídico. É imperioso, como o investigador, encaixar todas as peças do quebra-cabeça de um modo que a imagem possa aparecer de uma vez. Como estas relações vão se desenvolver e como essas orientações vão se conectar? Na extensa linha do fio da história quais são os laços que serão amarrados para que a sucessão de pequenos eventos possa se tornar tão grande movimento? E, em especial para o prosseguimento da pesquisa a partir do próximo tópico, o que vem a ser este surto, e, quais ideias são estas que se originam a partir dele?

\section{O Movimento Crítico e o Surto de Novas Ideias no Brasil.}


O termo "surto de novas ideias" é atribuído a Sylvio Romero (1906) em seu discurso de recepção a Euclides da Cunha ${ }^{4}$. Dentre outras coisas, Romero (1906) argumenta que até o ano de 1868 a filosofia naturalista, católica e eclética não havia sofrido nenhuma oposição por parte dos brasileiros que aceitavam a autoridade do Imperador sem muito questionamento. É então que um movimento subterrâneo desvela o sofisma da coroa brasileira e desestabiliza tudo fazendo com que, através do movimento liberal, novas ideias passem a surgir, ganhar força e acabar por demarcar todo este período. Estas novas ideias podem ser expostas de modo preliminar como o "positivismo, evolucionismo, cientificismo na poesia e no romance folklore, novos processos de crítica e da história literária, transformação da intuição do Direito e da política, tudo então se agitou e o primeiro brado de alarma partiu da Escola do Recife" (ROMERO, 1906).

Para Sônia Gomes (1986) este período, além de marcar o lançamento das primeiras bases de um regime científico no Brasil, também constitui um marco de definições e diferenciações (p. 14). O sentido desta frase é demonstrar que o país está passando por um processo de transição que compreende um verdadeiro abalo nas estruturas de cognição primária, sendo necessário retroceder na episteme para reintrodução dos fundamentos do conhecimento e, deste modo, inaugurar um novo período, este mais científico do que o passado. As faculdades orientavam-se pelo ecletismo e pelos princípios escolásticos e foi o atraso da estrutura social que despertou na elite brasileira a necessidade de construção de novo arcabouço de ideias que fosse capaz de estimular uma reestruturação e uma modernização da sociedade pátria (GOMES, 1986, p. 14).

A autora ainda suscita que não havia, no Brasil, naquela época, muita alternativa além do positivismo, porque não se tinham mentes preparadas para conhecer do Idealismo hegeliano, não se tinha uma indústria, ou uma organização social, capaz de conceber os conceitos do Materialismo marxista e, pouco se tinha de anotações a respeito do kantismo (GOMES, 1986, p. 15). Era necessário que as ciências

\footnotetext{
${ }^{4}$ Não é diferente do que explica Adeodato (2003) quando assevera que "deve-se a Sylvio Romero o termo, usado para designar o movimento intelectual que começou por volta de 1860 e foi até o começo do século XX. Reinavam uma filosofia idealista e eclética, assim como ideias monárquicas e a tradição do feudalismo nordestino, dos senhores de terras explorando os trabalhadores; vigorava também um certo romantismo no plano intelectual e a mentalidade geral era conservadora. Começa então, no dizer de Syvio Romero 'um surto de ideias novas a assolar o País', buscando os jovens professores recifences apoio no positivismo de Augusto Comte e nas variações de Littré, Taine, Noiré e outros” (p. 304).
} 
propusessem uma síntese totalizante que só foi possível, naquele momento, através dos argumentos da lei dos três estados e da religião da humanidade constantes na filosofia positiva, o que caracterizou, portanto, o cientificismo brasileiro do surto de novas ideias (GOMES, 1986, p. 15). Não é diferente da visão de Paim (1997) a respeito do tema, para quem a insuficiência de um espírito científico no Brasil fez com que as cogitações filosóficas fossem desenvolvidas a partir da referência externa com autores estrangeiros, podendo dividir os interessados no tema em três categorias: a) os pertencentes ao sensualismo metafísico francês que aderiram ao ecletismo; b) os pertencentes à reação neocatólica e; c) os positivistas que aderem as ideias de Comte e Darwin (p. 20).

O recrudescimento do desinteresse pelo ecletismo na própria França fez com que não houvesse muitas produções locais relativas ao tema que fossem capazes de fomentar os ávidos leitores brasileiros (PAIM, 1997, p. 20). Isso fez com que os trabalhos de Mont'Alverne e Ferreira França fossem objeto de ferrenhas críticas pelos insatisfeitos com as teses sustentadas por eles. De acordo com Paim (1997), uma das críticas mais importantes foi feita contra a obra de Domingos Gonçalves de Magalhães que publicara seu manual "Fatos do Espírito Humano", cuja orientação é herdada de Mont'Alverne e Cousin, porém, sem a mesma profundidade de pensamento que ambos de acordo com Sylvio Romero (p. 21). Entretanto, a crítica mais ácida sobre esta obra, em particular, e sobre a filosofia eclética em geral, ocorrerá em 1869, com Tobias Barreto de Menezes (1977) que irá atacar o livro de Magalhães. Aquelas alturas a brochura era o único (e o primeiro) manual de filosofia escrito no Brasil, tornando-se alvo para as mais diversas posições (p. 90). A crítica desenhada por Tobias (1977) neste ensaio beira um argumento ad homini, quando ataca as escolhas dispositivas da retórica de Magalhães, acusando de acreditar ter descoberto algo novo na filosofia (p. 92), mesmo não conhecendo inteiramente os reflexos da filosofia alemã na França, ou, quiça, na obra de Victor Cousin (p. 94). É uma questão de referência e uma escolha discricionária por alocar a verdade na visão exclusiva de um autor enquanto paradigma sustenta Tobias (1977)

"O positivismo na Europa se exprimia por órgãos tais como Littré e Stuart Mill. O hegelianismo era atacado por muitos, sustentado e professado por Vera. Na Itália, onde o nosso filósofo estivera como encarregado de negócios, fulguravam os grandes nomes de Gioberti e de Rosmini. No mundo filosófico fazia-se ouvir o embate das mais fortes discussões movidas pelos mais robustos combatentes. E no 
entanto o Sr. Magalhães nada ouviu! Não se pode, não se deve desculpar ao ilustre filósofo-poeta-diplomata semelhante indiferença; tanto mais quanto ele, deixando o que melhor importava, ocupou-se muito de refutar o refutado, usando de velhos e debilíssimos argumentos". (MENEZES, 1977, p. 94).

Tobias (1977), entretanto, dirige-se especificamente ao capítulo VIII da obra de Magalhães para investigação da teoria do duodinamismo como sendo aquela "que tira a sensibilidade da alma espiritual para atribuí-la a um princípio diverso" (p. 94). Gonçalves de Magalhães visa distinguir, além das categorias "corpo" e "alma" uma terceira, a sensibilidade como um a priori para qualquer tipo de conhecimento humano, a resposta de Tobias (1977) ainda reside no fato de que a ciência não pode deixar de falar uma linguagem específica e excluir de sua apreensão a língua comum, do cotidiano, ou seja, a premissa maior para derrubar o primado da sensibilidade é a simples apreensão de que ela não passa de uma intuição, um palpite, um exercício divagatório quando não mensurada e reduzida a um método (p. 95-7). Com estas acepções da crítica de Tobias (1977) ao Ecletismo, percebe-se sua aproximação com um positivismo metodológico. É bastante dizer que ele foi fortemente influenciado neste período pelo primeiro Ihering, portanto, um adepto da positivação, simplificação e esvaziamento ontológico do Direito.

Gomes (1986) entende que, da necessidade de esvaziar-se a estrutura argumentativa fornecida pelo espiritualismo eclético e pelo direito natural, os temas do evolucionismo darwinista, o positivismo comteano, ou de Littré, juntamente com a filosofia liberalista conseguiram lograr êxito em se inserir, definitivamente nos debates acadêmicos da Faculdade do Recife (p. 21). Neste sentido, o contexto histórico de ascensão do movimento liberalista no Brasil contribui sobremaneira para que se possa instituir o cenário ideal para que o surto possa ocorrer. Novamente, Gomes (1986) assevera que em 1868 começa o levante do movimento liberal em face ao conservadorismo dominante no poder, narrando a autora que "liberais históricos e progressistas se unem; a monarquia começa a ser contestada, considerando-se o poder moderador como ditatorial" (p. 29). Este levante começa com a tomar forma com a organização de um Centro Liberal que será dividido em diretórios e círculos, e, que se estratificará na Corte, Províncias e municípios fazendo frente e criticando as posições políticas do governo conservador (GOMES, 1986, p. 29). 
É somente no ano seguinte, depois de alguma perseguição dos Imperialistas, que o Centro Liberal lança o seu Manifesto reivindicando, dentre outras coisas, pautas relativas á: a) reforma eleitoral; b) reforma judiciária e policial; c) abolição do recrutamento; d) abolição da guarda nacional e; e) abolição da escravatura ${ }^{5}$ (GOMES, 1986, p. 30). Além da extensa lista de autoridades ${ }^{6}$ que assinaram tal documento, também é possível notar que a imprensa da época se cindiu em torno da polêmica entre o Liberalismo e o Conservadorismo ${ }^{7}$. Outros fatores passam a contribuir para o pensamento liberal ganhe força e comece o clamor pela reforma política e a instituição de uma República no Brasil, fato este que veio a ocorrer somente em 1889, com a proclamação da República Velha. Ao passo disso, Gomes (1986) ainda indica alguns fatores relevantes que vão encaminhando a noção da introdução de novas ideias no país: a) a abolição da escravatura leva ao questionamento sobre a propriedade como forma de manutenção de domínio econômico e, consequentemente, das diferenças; b) a migração de povos estrangeiros e sua dificuldade de inserção na sociedade brasileira desvela a diversidade cultural existente no país e; c) a Religião não deixa de ofertar uma resistência no processo de modernização do pensamento, pois há resposta da Igreja com a substituição dos professores por Padres, e, notadamente, pelo papel que a Maçonaria desempenhou na política brasileira (sem abandonar determinados valores cristãos) (p. 31-43).

É por meio destas questões que a desconstituição do Poder Moderador, enquanto um poder pessoal do rei, que o ideário presente no modelo federalista americano, aquela altura já conhecida pelos europeus, começa a ganhar adeptos no Brasil. Pode-se dizer que, em matéria de gênese histórica, este movimento de libertação da opressão dos resquícios do conservadorismo português existente no país é um dos fatores que origina o espírito combativo que marcará a identidade política do povo brasileiro, que pode chegar até a ser enganado por uma retórica protecionista, mas, que não tarda em buscar

\footnotetext{
${ }^{5}$ Ressalta Gomes (1986) que, para o Centro Liberal, a abolição deveria se dar de modo gradativo, e não geral, compreendendo o custo das alforrias e dando predileção aos nascituros (p. 30).

${ }^{6}$ Dentre as diversas autoridades que assinam o documento é possível encontrar os nomes de "José Thomaz Nabuco de Araújo, Bernardo de Sousa Franco, Zacarias de Goís e Vasconcelos, João Lustosa da Cunha Paranaguá, Antônio Marcelino Nunes Gonçalves, Theophilo Benedicto Ottoni, Francisco Octaviano de Almeida Rosa" (GOMES, 1986, p. 30).

${ }^{7}$ Gomes (1986) salienta que "foram muitos os jornais da época que se envolveram no problema político, sinal de que os liberais se uniram em torno de seus ideais; entre esses jornais, cita Vamireh Chacon: $O$ Diário da Bahia (Bahia), A Opinião Liberal (Rio), A Tesoura (Recife), O Diário de Pernambuco (Recife), A Opinião Nacional (Recife), O Democrata Pernambucano (Recife), O Progressista e $O$ Liberal, ambos de Recife; A Reforma Liberal (Manaus)” (p. 30).
} 
ativamente pelo avivamento da liberdade. De fato, James Holston (2013) perfaz uma análise muito acurada da formação do conceito de cidadania no Brasil, que passa por períodos diversos até que a mentalidade política possa se desenvolver através da atuação dos conselhos dos bairros nas cidades com grandes indústrias e, a partir daí, originar o Partido dos Trabalhadores, por exemplo (p. 69). Jessé de Souza (2019), de outra sorte, prefere estabelecer estas relações demonstrando que a construção do conceito de Elite no Brasil é um dos fatores determinantes para que se manifeste, reiteradamente, um atraso entre nós brasileiros.

\section{A expansão da Escola do Recife pelo Brasil.}

Antônio Carlos Wolkmer (2003) assevera que a implantação dos cursos de direito no Brasil acaba por refletir as exigências de uma elite que se tornará a sucessora da dominação colonizadora através da concretização da independência político-cultural, dando margem para o desenvolvimento das instituições que acabariam por administrar e gerir a estrutura do Estado (p. 80). Ainda neste diapasão, dois objetivos principais das faculdades de direito podem ser elencados: a) servir de polo de irradiação de um pensamento liberal e; b) dar efetivação institucional ao pensamento liberal (WOLKMER, 2003, p. 80-1). O grande paradoxo, portanto, é que o Ensino Superior no Brasil institui uma grande inversão de valores pois apesar de divulgar a palavra do liberalismo grande parte da população, eminentemente agrária, encontrava-se excluída da Academia e marginalizada. Recife, especificamente, expressava uma forte tendência para erudição, a ilustração e a recepção de teorias estrangeiras sendo responsável por introduzir o germanismo na cultura jurídica brasileira vindo, posteriormente, a se filiar no evolucionsimo e no monismo (WOLKMER, 2003, p. 82).

As teses levantadas pela Faculdade do Recife são irradiadas diretamente para as outras faculdades de direito que serão fundadas noutros Estados muito por conta dos discípulos e do legado recifense de fins do século XIX a meados do XX (CHACON, 2008, p. 139). Por meio do decreto n. 1.232-H, de 2 de janeiro de 1891, foi concedida a permissão para criação de faculdades livres, fossem privadas ou estaduais, fato que foi consolidado pela criação da Faculdade de Salvador e outra no Rio de Janeiro 
(CHACON, 2008, p. 139). Tendo sido a primeira faculdade da República, a Faculdade Livre de Direito da Bahia contou com cerca de vinte e dois catedráticos em sua composição original, tendo $60 \%$ deles se formado em Direito na Faculdade do Recife (CHACON, 2008, p. 140-1). De acordo com Vamireh Chacon (2008) a inclinação da pesquisa, consequentemente, foi diretamente ligada para as referências em Darwin (evolucionismo) e Heackel (monismo), que foram radicalizados por autores como Leovigildo Filgueiras, Virgílio de Lemos e Almáquio Diniz ${ }^{8}$, grupo este que ficou conhecido como "o grupo baiano" da Escola do Recife (p. 141).

No Rio de Janeiro, sempre houve uma reivindicação de criação de um estabelecimento de ensino superior, o que foi atendido, de acordo com Chacon (2008) “com a criação da Escola Politécnica em 1874, sucessora da Escola Central para engenheiros civis de 1858, continuadora da Real Academia de Artilharia fundada não só para engenheiros militares" (p. 143), a Escola Politécnica acabou sendo convertida, em 1937 na Escola Nacional de Engenharia da Universidade do Brasil, e, posteriormente, em Universidade Federal do Rio de Janeiro ${ }^{9}$. Foi Sylvio Romero a principal influência do pensamento de Recife na Faculdade Livre de Direito do Rio de Janeiro e, o fato de ter se tornado a voz do movimento, o levou a ser amplamente reconhecido na Academia Brasileira de Letras, assim como seu pensamento filosófico (de uma filosofia brasileira), suas críticas literárias, e sua notável adesão ao kantismo.

\footnotetext{
${ }^{8}$ Para Chacon (2008) Almáquio Diniz foi aquele que mais se destacou dentre os professores do grupo baiano, "muito influenciado pelos Estudos de direito de Tobias Barreto, mais a Concepção monística do universo de Fausto Cardoso e os Ensaios de filosofia do direito de Sílvio Romero, nestas linhas Almáquio Diniz confessa ter escrito seus Ensaios filosóficos sobre o mecanicismo do direito (1906), Questões atuais de filosofia do direito (1909) e o Curso de enciclopédia jurídica ou uma teoria geral do direito (1913). Protestou contra uma das reformas que transformou o ensino de filosofia do direito em enciclopédia jurídica através do livro A reforma do ensino (A nova classificação da filosofia do direito) (1925) e discordou frontalmente, a propósito, de Filinto Bastos, Católico tradicionalista, porém reconhecido jurista. Almáquio Diniz, que conheceu de perto seu antecessor Leovigildo Filgueiras, declarou-o 'um spencerista apaixonado', 'abeberando-se em Tobias Barreto'. Seu 'programa tinha muito mesmo do índice dos Estudos de direito, de Tobias Barreto, obra de publicação póstuma dirigida por Sílvio Romero"”. (p. 142).

${ }^{9}$ Chacon (2008) contribui ainda descrevendo detalhes a respeito da criação da Faculdade Livre de Direito do Rio de Janeiro que ocorreu "no Mosteiro de São Bento naquela cidade em 31 de maio de 1891, com personagens políticos da época, entre os quais Ubaldino do Amaral, Serzedelo Corrêa e Rangel Pestana. Interrante notar a presença de José Higino Duarte Pereira polemizador contra Tobias Barreto no recife, José Higino tornado ministro do Supremo Tribunal Federal. Memória histórica de 1907, publicada na Revista da Faculdade Livre de Direito da Cidade do Rio de Janeiro em 1908, ano IV (volume IV, páginas 94 e 95) que omite o nome de Sílvio Romero entre eles, mas o diretor Leôncio de Carvalho o inclui no relatório do Décimo aniversário da fundação da Faculdade, publicado na mesma revista em 1910”. (p. 143-4).
} 
Em Outro Preto, Minas Gerais, a Faculdade Livre de Ciências Jurídicas e Sociais é criada em 1892 e transferida para Belo Horizonte em 1898. Em menor quantidade de professores oriundos do Recife, a maioria esmagadora havia se formado em São Paulo, a adesão ao cientificismo filosófico em contraposição ao catolicismo tradicionalista e ao conservadorismo encontra espaço na produção intelectual de Augusto Lima, através da leitura de Tobias Barreto e Sylvio Romero (CHACON, 2008, p. 146). Espraiando-se pelo Estado de Goiás, os discípulos de Tobias Barreto e companhia encontram admissão na Faculdade Livre de Ciências Jurídicas e Sociais em 1916, tendo inclusive a presença de Cristiano Cordeiro, pernambucano, e colega de João Barreto de Menezes, filho de Tobias $^{10}$ (CHACON, 2008, p. 147). Em Porto Alegre, o destaque é feito para o magistério em Direito Penal de Francisco de Souza Ribeiro Dantas e sua especial inclinação para a obra "Menores e Loucos no direito criminal" de Tobias Barreto (CHACON, 2008, p. 149). Noutro polo, o Norte, é possível encontrar a seguinte passagem

\begin{abstract}
"Nos fins do século XIX e princípios do XX a imigração nordestina rumou mais ao Norte que ao Sul; motivo: o auge do ciclo da borracha, que transformou Belém e Manaus em tão ricas, que se tornaram metrópoles à beira da selva amazônica. Em 1901 um grupo de ilustres juristas criou em Belém do Pará o Instituto Teixeira de Freitas, almejando a fundação da Escola Livre de Direito criada no ano seguinte, instalada ainda em 1902, pelo decisivo apoio do governador do Pará, com Augusto Montenegro, ele próprio bacharel pela Faculdade de Direito do Recife em 1886, portanto aluno de Tobias Barreto e colega contemporâneo dos seus primeiros importantes discípulos. Não era o único em Belém do Pará; a seu lado estavam vinte e um formados pela Faculadde do Recife, enquanto apenas dois por outras, um pela de São Paulo e outro pela da Bahia, ao lado de dois médicos das matérias didáticas respectivas. Mesmo em meio às suas tarefas políticas e administrativas, Augusto Montenegro exerceu a cátedra de economia política, finanças e contabilidade, desdobrada nos tempos dos seus sucessores" (CHACON, 2008, p. 150).
\end{abstract}

\footnotetext{
${ }^{10}$ Novamente, Chacon (2008) acrescenta que "filho muito zeloso pela memória paterna e seu defensor em memoráveis campanhas políticas democráticas e populares. Ambos [Cristiano Cordeiro e João Barreto] fizeram parte da turma de 1918. Cristiano Cordeiro foi adiante, tornou-se um dos fundadores do Partido Comunista no Brasil, ao lado de Astrojildo Pereira e alguns poucos outros, antes mesmo da entrada de Luís Carlos Prestes. Cristiano Cordeiro participou a contragosto da Insurreição de 1935, foi preso e enviado, pelo autoritário Estado Novo varguista, a uma espécie de exílio interno no outrora tão longínquo Goiás, onde encontrou a simpatia de Pedro Ludovico, interventor no estado e principal animador da construção da nova capital, na qual aceitou os serviços de professor de Cristiano Cordeiro na recémtransferida Faculdade de Direito" (p. 148).
} 
Três nomes são citados como grandes continuadores da tradição da Escola do Recife em Belém do Pará, sendo eles Samuel da Gama e Costa Mac-Dowell ${ }^{11}$, Justiniano de Serpa ${ }^{12}$ e Raimundo de Farias Brito (CHACON, 2008, p. 150). Este último, com todas as deferências, merece um comentário mais extenso a respeito da contribuição para a fundação de uma tradição jurídica paraense. Bacharel em Direito pela Faculdade de Direito do Recife em 1884, presenciou o grande apogeu crítico da Faculdade e da produção intelectual de Tobias Barreto (CHACON, 2008, p. 151). Enveredando para política em seu estado natal, acabou indo para Belém por ventura do falecimento de seu pai e de sua esposa, oportunidade na qual, também, escreveu o livro "Finalidade do mundo" e iniciou a escrita de "Filosofia do espírito". Professor substituto da cadeira de filosofia do direito foi dito por Sylvio Romero como sendo um dos leitores mais aprofundados em Spinoza, Kant, Mill e Spencer (CHACON, 2008, p. 152). A respeito da filosofia professada por Farias de Brito, Chacon (2008) argumenta que "o idealismo de Farias de Brito, único pensador brasileiro original sistêmico até então, em parte é indiretamente resposta ao agnosticismo kantiano tobiático, após a sua fase materialista de Haeckel" (p. 168-9).

A respeito deste tema foi feita uma consulta ao Instituto Silvio Meira, que por meio de seu Presidente Professor André Meira forneceu interessante bibliografia sobre os perfis parlamentares com destaque ao Deputado Federal José Augusto Meira Dantas, mais conhecido como Augusto Meira. Tendo iniciado seus estudos primários em humanidades com seu pai, Augusto Meira cursou Direito na Faculdade de Recife se graduando em 1899, volveu para o Rio de Janeiro após sua graduação e, incontinenti, lhe foi oferecida a Promotoria da cidade de Santarém (PA) (MEIRA, 1993, p. 20-2). Por conta de seu pensamento lúcido e avançado, acabou sendo transferido para comarca da capital onde exerceu o cargo na companhia de Farias Brito e Avertano Rocha e, com

\footnotetext{
${ }^{11}$ A respeito deste nome,"Samuel Mac-Dowell, de uma família na qual o nome se repete, é dos da Faculdade de Direito do Recife, ali vindo a ser professor de direito comercial e companheiro na banca de advocacia do pai. De volta a Belém tornou-se presidente da Ordem dos Advogados local, deputado estadual e um dos fundadores da Faculdade Livre de Direito" (CHACON, 2008, p. 150-1).

${ }^{12}$ Sobre este segundo nome, "Justiniano de Serpa, também egresso da Faculdade de Direito do Recife, cedo chegou a deputado provincial no Ceará natal no tempo da Monarquia, em seguida professor no Liceu Cearense, defensor da abolição da escravatura na Câmara e nos jornais; ao perder o mandato pela proclamação da República, logo foi eleito deputado à Assembleia Constituinte Federal e governador do Ceará. Quando mais uma vez deputado, rompeu com a ditadura do marechal Floriano Peixoto, solidarizando-se com Epitácio Pessoa e J. J. Seabra, então na oposição, tendo de transferir-se a Manaus e de lá a Belém, onde voltou a eleger-se deputado federal. Está entre os professores fundadores da Faculdade Livre de Direito de Belém do Pará" (CHACON, 2008, p. 151).
} 
exceção da cadeira de Medicina Legal, Augusto Meira lecionou todas as outras disciplinas do curso de Direito em Belém (MEIRA, 1993, p. 23). Augusto Meira, tanto em sua vida como Parlamentar, Promotor, quanto como Professor levou a frente o espírito vanguardista dos professores do Recife.

\section{Críticas e Respostas acerca do movimento recifense.}

Como se pode observar, a contribuição da Escola do Recife para construção de uma tradição jurídica brasileira é enorme e deixa seu legado sobre a criação de vários outros centros de estudo no Brasil. Porém, é importante salientar que não existem somente aspectos positivos a serem investigados no que tange à contribuição original dos pensadores recifenses que, muitas vezes eram acusados de cometer uma deslealdade acadêmica para com os outros autores estudados na medida em que precipitações poderiam ser cometidas quando não há um empenho em compreender a obra do escritor estrangeiro antes de criticá-la. Adeodato (2003) lembra que isso se dá pelo fato de os professores do movimento acreditaram que o pensamento dos professores importados não estava pronto e acabado, pendente, deste modo, de uma contribuição autêntica para que pudessem ser aplicáveis no Brasil (p. 305). A partir daí que surge este debate acerca da originalidade e da fidelidade acadêmica dos pertencentes ao movimento ${ }^{13}$.

Entendida de um modo mais ampliado a crítica pode ser expressa a partir da noção de recepção. Quando o anfitrião recebe um convidado em sua festa ele não está somente deixando com que uma pessoa estranha adentre em sua residência, mas, também, convidando-a a sentir à vontade. Ou seja, ele dá certa liberdade para que o convidado possa interagir com o seu espaço e compartilhar dele com o anfitrião. Em matéria de recepção do pensamento estrangeiro estende-se o mesmo convite aos autores,

\footnotetext{
${ }^{13}$ João Maurício Adeodato (2003) pontua que "No Brasil da época, de modo geral, só eram estudados os autores e as culturas portuguesa e francesa. Havia, porém, de parte de Tobias, uma nítida preocupação em atualizar-se frente às novas publicações da Europa como um todo, para que evidentemente prestou-se sua fluência na leitura da língua alemã, competência rara nos professores do Recife. Ainda que influenciado pelas ideias europeias, porém, Tobias e seus amigos não as encaravam como prontas e acabadas, sempre procurando emprestar-lhes crivo crítico. Daí o debate sobre a fidelidade e acuidade das análises e discussões. Esse aspecto de não-subserviência talvez tenha sido o principal fator da originalidade que resultou do movimento recifense, em que pese seu caráter periférico em relação aos debates no centro mais desenvolvido. Se a originalidade vem ou não da ignorância do 'verdadeiro sentido' dos autores europeus, este parece problema de menor relevância. De toda forma, o grupo de Tobias não se preocupava muito em elaborar fichas de leituras fiéis de obras e autores europeus, cuidando de elaborar um pensamento próprio" (p. 305).
} 
para que compartilhem suas experiências e se sintam à vontade para ficar em casa. Consequentemente, é preciso buscar saber quem é essa pessoa que está sendo convidada a conhecer o interior da casa, deve-se dedicar tempo à compreensão das teses que pretendem ser recepcionadas. Este sentido de recepção fica maculado quando se parte de uma pré-concepção crítica a respeito do pensamento que se recepciona. Então, o processo de criação, como um todo, acaba se contaminando desde a raiz.

Em consequência, é possível aduzir que não há autenticidade no pensamento da Escola do Recife, porque suas críticas são projeções dos seus pré-conceitos acerca da obra dos autores a quem estão se referindo. Bastaria contra-argumentar as críticas do surto de novas ideias dizendo “...mas, não foi isso que esse autor quis dizer..."; ou, "o você está dizendo é ideia sua e não do autor fulano de tal". De fato, é um argumento pertinente, autenticidade verdadeira, originalidade própria, é uma possibilidade crível na sociedade contemporânea? Os processos de dominação do neocolonialismo advogam que a dominação intelectual se dá por meio da justaposição da racionalidade externa com a interna, o que significa que é um imperativo receber sem criticar. Porém, olhando pelo outro lado, até que ponto a crítica pela crítica forma uma identidade? A negação absoluta de certeza não é, por assim dizer, um tipo de certeza?

Outro ponto negativo acerca da proposta metodológica do movimento recifense diz respeito à adoção do germanismo e a discussão de referências europeias. A negatividade deste argumento está diretamente ligada ao que foi chamado, no parágrafo acima, enquanto um neocolonialismo. O Brasil era refém dos estudos Portugueses e Franceses, havia um dogmatismo formal quanto ao modo como se devia apreender o conteúdo destas teses, porém, o germanismo, inserido no direito por Tobias Barreto se justifica pela necessidade de o Brasil se adequar às exigências de uma racionalidade filosófica que se encontrava no mais avançado estágio (ainda que no continente europeu), na Alemanha. Razão pela qual Tobias não só se tornou fluente na língua alemã, como também, produziu uma série de textos em alemão que foram publicados naquele país tornando-lhe referência nas ciências criminais com destaque para obra "Estudos Alemães", e o famoso discurso liberal republicado integralmente em língua alemã, "Um discurso em mangas de camisa".

\section{Conclusões.}


Por pelo menos três frentes diferentes o legado da Escola do Recife pode ser atacado e é possível sintetiza-los do seguinte modo: a) apesar de uma linguagem liberal, o monopólio do acesso ao conhecimento erudito era exercido por uma elite que substitui a monarquia durante a Primeira República; b) a filosofia crítica exercida pelos professores que seguiam a retórica tobiática pode ser interpretada como uma deslealdade acadêmica com o sentido original das obras devido a uma interpretação orientada por pré-conceitos ilegítimos e; c) a opção pelo estudo do pensamento alemão, introduzindo o germanismo no Brasil, indica a manutenção do processo de colonização intelectual que acaba por manter a estrutura do sistema mundo e as diferenças entre centro e periferia. Ainda, para Adeodato (2003), pode-se incluir, também, a aparente falta de unidade entre os autores pertencentes ao movimento, crítica essa que é afastada por ele ao demonstrar que existem vários pontos de conexão entre eles ${ }^{14}$ (p. 320).

É difícil discordar da leitura histórica que fundamenta o primeiro argumento, porém, contra ele seria possível levantar a tese de que o discurso acadêmico nem sempre alcança seus objetivos na prática política. Se se analiser a própria história do pensamento filosófico será possível encontrar casos em que a teoria propugna por um caminho, mas, os interesses humanos e as relações de poder manipulam estes argumentos e os desvirtuam para manter as estruturas e as instituições. Sócrates, por exemplo, vê a dialética se tornar "rebeldia" e o discurso político marginaliza a filosofia ao ponto de Platão defender a República de filósofos. E, no Brasil, o discurso acadêmico liberalista enfrenta o desafio de conscientizar as grandes massas dentro de um ambiente que fomentava a desinformação (e conseguia fazê-lo de modo prático). É bastante acertada, portanto, a perspectiva de Jessé de Souza (2019) para quem a gênese dos problemas atuais é encontrada a partir da compreensão das questões que originam a produção de diferença histórica no Brasil ${ }^{15}$.

\footnotetext{
${ }^{14}$ Nesse sentido, "muito embora a discussão a respeito, parece que realmente houve unidade de pensamento no Recife, inspirada no movimento neokantiano e buscando derrubar tanto o materialismo histórico como o positivismo ortodoxo e o espiritualismo aristotélico-tomista. Um dos elementos dessa unidade se dá em torno da obra de Kant, como dito acima, através de cuja obra eram filtradas diversas fontes aproveitadas pelos membros da Escola. Eles não propriamente aderiram nem tampouco permaneceram acompanhando a evolução das principais correntes filosóficas que os influenciaram, aproveitando apenas aquilo que os ajudava no combate ás outras correntes, dentro da realidade local" (ADEODATO, 2003, p. 320).

${ }^{15}$ Para um esclarecimento do argumento levantado aqui "O que é necessário compreender é o vínculo orgânico entre a criação do bode expiatório da corrupção política e o processo de invisibilização do saque,
} 
De outra sorte, a resposta para as duas outras críticas pode ser aglutinada em cima de um argumento muito bem ponderado por Adeodato (2003) para quem os autores do movimento procuravam solucionar problemas locais, brasileiros, particulares e este singular motivo os impossibilitava de receber as teses estrangeiras de um modo acrítico (p. 320). É justamente esta tentativa de atender às necessidades locais que faz com que se constitua uma independência cultural do povo brasileiro e a ideia de uma originalidade de pensamento, muito embora a própria ausência de uma tradição filosófica no Brasil contribuísse negativamente para a absorção destas novas ideias (ADEODATO, 2003, p.321). Uma das maiores problemáticas enfrentadas na presente tese era justamente essa, a noção exata de qual tipo de recepção é feita pela Escola do Recife, e a ideia de uma originalidade de pensamento atribuída ao movimento. De modo que, apesar de as próprias teses que estão sendo recepcionadas não estarem prontamente acabadas e em constante mutação o processo de recepção crítica feito pelo movimento recifense, e posteriormente espalhado por todo o Brasil, demonstra qual a identidade jurídica que se constrói a partir do século XIX.

Em conclusão, parece precipitado o argumento que acusa o Surto de Novas Ideias de ser uma apropriação indevida das proposições filosóficas que ele se preocupou em estudar. Tome-se como base desta precipitação uma fala do Prof. Robert Alexy no Autumn International Legal Seminar realizado em Março de 2014 na UNOESC Chapecó/SC. Quando perguntado sobre a aplicabilidade de sua famosa fórmula da ponderação, no modelo mais complexo proposto por ele em ocasião do evento, alguns casos práticos foram levantados para que pudesse demonstrar como eles seriam resolvidos pela técnica de ponderação e aplicação da fórmula peso. Porém, antes de fazê-lo o professor asseverou, em um tom sério e semblante fechado, que, tanto na introdução de sua teoria da argumentação jurídica quanto em sua teoria dos direitos fundamentais, ele estava se reportando para a cultura e para constituição alemã. Tentar solucionar questões relativas ao infanticídio na aldeia indígena ou sobre o aborto do feto anencéfalo usando sua formula peso sem considerar as variáveis culturais, históricas e

mil vezes maior, promovido pela pequena elite de proprietários sob o comando do rentismo hoje dominante. Assim, só para ter uma ideia do tamanho da patranha basta comparar a sonegação abertamente ilegal de impostos da elite, que é de 500 bilhões de dólares, com o dinheiro recuperado pela Lava Jato depois de cinco anos de 'trabalho', que não chega a um bilhão de dólares. Essa é a distância entre a corrupção real e a corrupção dos feitos de tolos. Quem não percebe o vínculo orgânico de reciprocidade entre os dois fatos foi efetivamente feito de bobo" (SOUZA, 2019, p. 249). 
sociais do Brasil, adequando as premissas teóricas para estas necessidades é um salto no vazio. As respostas podem fazer certo sentido, ou sentido nenhum, deixando de ser questões analíticas e se tornando em hermenêuticas.

Tal alegação de um alemão em terras brasileiras a respeito da recepção é a confirmação da resposta de Adeodato (2003), muito embora seja possível identificar alguns percalços no caminho, e que haja espaço para tecer críticas com consciência histórica, não deve prevalecer injustiça com a contribuição intelectual e cultural do surto de ideias proposto pela Escola do Recife. Sua originalidade não está no fato de deslocar a centralidade do sistema-mundo para a periferia, em vários aspectos encontra-se sim uma manutenção do status quo ${ }^{16}$ (como por exemplo Tobias sendo considerado um expoente do pensamento alemão na América latina pelos próprios alemães, ou, a manutenção de fontes estrangeiras). Contudo, é impossível constituir uma tradição inteiramente nova sem referências ao pensamento europeu. Porém, é perfeitamente possível adequa-lo à realidade local. Isto não havia sido feito antes na magnitude e na proporção do que foi realizado pela Escola do Recife, elevando-a ao patamar que merece ocupar e justificando a seleção dela para a discussão sobre a gênese da identidade jurídica e dos processos de recepção e formação do pensamento jurídico no Brasil.

\section{Referências Bibliográficas.}

ADEODATO, João Maurício. (org.). Continuidade e Originalidade no Pensamento Jurídico Brasileiro: análises retóricas. Editora CRV. Curitiba - Brasil. 2015.

( org). Jhering e o direito no Brasil. Recife: UFPE, 1996.

ADEODATO, João Maurício. O Positivismo Culturalista da Escola do Recife. Revista Novos Estudos Jurídicos - Volume 8 - N. 2 - p. 303-326. Maio/ago. 2003.

Filosofia do Direito - uma crítica à verdade na ética e na ciência (através de um exame da ontologia de Nicolai Hartmann). 2 ed. São Paulo: Saraiva, 2002.

\footnotetext{
${ }^{16}$ Ainda, será mesmo possível dizer que hoje estamos completamente livres do colonialismo?
} 
BARROS, José D'Assunção. Teoria da História - Os Primeiros Paradigmas: Positivismo e Historicismo. Volume II. Petrópolis, RJ: Vozes, 2013.

A Escola dos Annales e a crítica ao Historicismo e ao Positivismo. Revista Territórios e Fronteiras. V.3. N.1. - Jan/Jun. 2010.

CHACON, Valmireh. Formação das Ciências Sociais no Brasil: Da Escola do Recife ao Código Civil de 1916. (...).

FERREIRA, Pinto. A Faculdade de Direito da Escola do Recife. Revista de informação legislativa. v. 14, n. 55, p. 5-20, jul./set. 1977. Disponível em: http://www2.senado.leg.br/bdsf/handle/id/181024

GOMES, Sonia. Surto de novas ideias: década de 1868 - 1878: Aspectos Fundamentais. Dissertação de Mestrado apresentada ao Departamento de Filosofia da Universidade Gama Filho. Rio de Janeiro- RJ. 1986.

HOLSTON, James. Cidadania Insurgente: disjunções da democracia e da modernidade no Brasil. Tradução Claudio Carina. Revisão técnica Luísa Valentini. Companhia das Letras. São Paulo - SP. 2013.

HORA, Graziella Bacchi. Fragmentação Erística na Escola do Recife: uma leitura retórica da filosofia de Tobias Barreto. Tese de Doutorado apresentada ao Programa de Pós-graduação em Direito da Faculdade de Direito do Recife. Recife. 2010.

. Tobias Barreto e a crítica moderada ao positivismo. Revista Caderno de Relações Internacionais. Vol 4. N. 7. Jul-dez. 2013.

LIMA, Hermes. Tobias Barreto: a época e o homem. Companhia Editora Nacional. São Paulo-Sp. 1939.

LINS, Ivan. História do Positivismo no Brasil.Companhia Editora nacional. São Paulo- SP. 1926.

MEIRA, Augusto. Discursos Parlamentares. Seleção, introdução e comentários de Silvio Meira. Brasília: Câmara dos Deputados Federais. 1993. 
PAIM, Antônio e MERCADANTE, Paulo. Apresentação e Introdução. In. MENEZES, Tobias Barreto. Estudos de Filosofia. 2 ${ }^{a}$ Ed. Editorial Grijalbo. 1974.

PAIM, Antônio. Os Intérpretes da Filosofia Brasileira - Estudos Complementares à História das Ideias Filosóficas no Brasil. Volume I. $3^{\text {a }}$ Ed. Editora UEL. Londrina. 1999.

A Escola do Recife: Estudos Complementares à História das Ideias Filosóficas no Brasil. Vol. V. Editora UEL. Londrina - PR. 1997.

ROMERO, Sylvio. Philosophia no Brasil: apontamentos para História da Literatura brasileira no século XIX. Ensaio Crítico. Tipografia da Deutsche Zeitung. Porto Alegre - SC. 1878.

SALDANHA, Nelson Nogueira. História das Ideias Políticas no Brasil. Editora do Senado Federal Brasília - DF. 2001.

SANTOS, Evandra Alves dos; LIMA, Jociene Santos; AMORIM, Nadir Araújo; SANTOS, Maria Cristina Santana dos. TOBIAS BARRETO: UMA LEITURA POÉTICA EM TEMPOS DE GUERRA. Disponível em: http://openrit.grupotiradentes.com:8080/xmlui/handle/set/2241 Acesso em: 05 Ago 2019.

SANTOS, Gustavo dos. Academia de direitos de São Paulo: cultura jurídica e política na formação dos bacharéis (1850-1870); orientação [de] Prof ${ }^{a}$. Dr ${ }^{a}$. Ilka Miglio de Mesquita - Aracaju: UNIT, 2015.

SOUZA, Jessé. A Elite do Atraso: da escravidão à Bolsonaro. 2. Ed. Saraiva. São Paulo - SP. 2019. 